\title{
Subject Index to Volume 40 - 2013
}

\section{C-FLUMAZENIL PET}

GABAergic Changes in 11C-Flumazenil PET in the

Drug-Naïve Stiff-Person Syndrome

(JAN)

\section{2q11.2 MICRODELETION}

Hippocampal Malrotation is Associated with

Chromosome 22q11.2 Microdeletion

(SEPT)

\section{4q21 DELETION SYNDROME}

Array CGH Analysis and Developmental Delay: A

Diagnostic Tool for Neurologists

(NOV)

ABSCESS

Pituitary Abscess: Review and Highlight of a Case

Mimicking Pituitary Apoplexy

(SEPT)

\section{ABSTRACTS \\ Canadian Association of Neuropathologists ABSTRACTS}

aCGH

Array CGH Analysis and Developmental Delay: A

Diagnostic Tool for Neurologists

$(\mathrm{NOV})$

\section{ACOUSTIC NEUROMA}

Recovery from Deafness in the Contralateral Ear of Surgery in NF 2 Patient

(SEPT)

\section{ACUTE FULMINANT HEPATIC FAILURE}

Acute Fulminant Hepatic Failure, Encephalopathy and Early CT Changes

(JULY)

\section{ACUTE HIV-1 INFECTION}

Bilateral Peripheral Facial Paralysis Combined with HIV Meningitis

(NOV)

\section{ACUTE ICHEMIC STROKE}

Association of Serum Bilirubin with Stroke Severity and Clinical Outcomes

\section{ACUTE PANCREATITIS}

Levetiracetam Induced Acute Pancreatitis Case in Pregnancy

(NOV)

\section{ACUTE SUBDURAL HEMATOMA}

Rapid Resolution of Acute Subdural Hematoma in a Coagulopathic Patient

(JULY)

\section{ACUTE TRANSVERSE MYELITIS}

Bacillus Thuringiensis Poisoning Related Acute Transverse Myelitis

(MAY)

\section{ADHESIVE CAPSULITIS}

Screening for Adhesive Capsulitis in the Timely

Diagnosis of Parkinson's Disease

(JAN)

\section{AIDS}

Bilateral Peripheral Facial Paralysis Combined with

HIV Meningitis

(NOV)

\section{ALZHEIMER'S DISEASE}

Meta-Analysis on the Association Between the TF

Gene rs 1049296 and AD

(SEPT)

Persistence with Cholinesterase Inhibitor Treatment in

Alzheimer's Disease

(SEPT)

\section{AMYLOID}

Cerebral Amyloid Angiopathy Presenting with TIA-like Episodes

(MAY)

\section{AMYLOIDOSIS}

Amyloid Myoneuropathy Mimicking Inclusion Body Myositis

(MAR)

\section{AMYOTROPHIC LATERAL SCLEROSIS}

Establishing a Canadian Registry of Patients with Amyotrophic Lateral Sclerosis

Epidemiological Surveillance of Amyotrophic Lateral

Sclerosis in Saguenay Region

(SEPT)

A Real-World Glimpse into the Epidemiology of ALS in Canada

(SEPT)

\section{ANEURYSM}

Hemiparkinsonism Due to Coiled Posterior Cerebral Artery Aneurysm

\section{ANGIOARCHITECTURE}

Factors Determining the Clinical Complications of

Radiosurgery for AVM

(NOV)

Symptomatic Cerebral Edema Following Radiosurgery for AVMs

(NOV)

\section{ANGIOCENTRIC}

45-Year-Old Female with a 25 Year History of Seizures

\section{ANGIOPATHY}

Cerebral Amyloid Angiopathy Presenting with TIA-like Episodes

(MAY)

\section{ANTEROGRADE AMNESIA}

Acute-Onset Anterograde Amnesia Caused by Isolated Bilateral Fornix Infarction

(SEPT)

\section{ANTI-GAD ANTIBODY}

GABAergic Changes in 11C-Flumazenil PET in the

Drug-Naïve Stiff-Person Syndrome

(JAN)

\section{APPARENT DIFFUSION COEFFICIENT}

The Value of GRE, ADC and Routine MRI in

Distinguishing Parkinsonian Disorders

(MAY)

ART

Preserved Drawing in a Sculptor with Dementia

\section{ASSESSMENT}

Discrimination of the Cognitive Profiles of MCI and

Depression using the KBNA

(SEPT)

\section{ASYMPTOMATIC CAROTID STENOSIS}

Diabetes, Intracranial Stenosis and Microemboli in

Asymptomatic Carotid Stenosis

(MAR)

\section{ATYPICAL PARKINSONISM}

The Value of GRE, ADC and Routine MRI in

Distinguishing Parkinsonian Disorders

(MAY)

\section{AUTONOMIC NERVOUS SYSTEM}

A Step Toward Moving Forward in Autonomic Nervous System Research

(NOV)

\section{AUTONOMIC REFLEX SCREEN}

The Autonomic Reflex Screen in Healthy Participants from Southwestern Ontario

(NOV)

AVM

Factors Determining the Clinical Complications of

Radiosurgery for AVM

(NOV)

\section{AWAKE CRANIOTOMY}

Wearable Video Display Allowing Freedom in Head

Positioning for Brain Mapping

Acute Neurological Complication in Awake Craniotomy; - A Diagnostic Dilemma (JULY)

\section{BACILLUS THURINGIENSIS POISONING}

Bacillus Thuringiensis Poisoning Related Acute

Transverse Myelitis

\section{BEHENIC ACID}

Can Behenic Acid (C22:0) Levels be a Prognostic

Factor in Glial Tumors?

(NOV)

\section{BEVACIZUMAB}

Bevacizumab Use for Recurrent High-Grade Glioma at McGill University Hospital

(MAR)

\section{BIOETHICS}

Priority Setting in Neurosurgery as Exemplified by an Everyday Challenge

(MAY)

\section{BLINK RATE}

Spontaneous Blink Rates in Children During Different Types of Eye Movements (SEPT)

BLOOD PRESSURE

Acute Neurological Complication in Awake Craniotomy; - A Diagnostic Dilemma

\section{BOTULINUM TOXIN TYPE A}

Effectiveness of BoNT A in Parkinson Disease Upper

Limb Tremor Management

(SEPT) 


\section{BRAIN ANATOMY}

Niels Stensen: A 17th Century Scientist with a Modern View of Brain Organization

(JULY)

\section{BRAIN ARTERIOVENOUS MALFORMATION}

Symptomatic Cerebral Edema Following Radiosurgery for AVMs

(NOV)

\section{BRAIN-DERIVED NEUROTROPHIC FACTOR}

Hydrogen-Rich Saline Attenuated Neuropathic Pain by Reducing Oxidative Stress

(NOV)

\section{BRAIN MAPPING}

Wearable Video Display Allowing Freedom in Head Positioning for Brain Mapping

\section{BRAIN METASTASES}

Calcified Brain Metastases from Osteosarcoma (MAR) The Technique and Cost of Radiosurgery for the

Treatment of 1-3 Brain Metastases

(NOV)

\section{BRAIN RESERVE CAPACITY}

Preserved Drawing in a Sculptor with Dementia

(SEPT)

\section{BRAINSTEM}

The Expressions of Wnt/ $\beta$-catenin Pathway-Related

Components in Brainstem Gliomas

(MAY)

\section{BRAINSTEM GLIOMA}

Correlation Between MRI Findings and Histological

Diagnosis of Brainstem Glioma

(MAY)

\section{BRAIN TUMOR}

Neurosurgical Management of Intracranial Metastatic

Mesothelioma

Diagnostic Challenges of Radiation Necrosis (NOV)

\section{BURDEN}

The Burden of Inpatient Neurologic Disease in a

Tropical African Hospital

\section{CALCA GENE POLYMORPHISM}

Calcitonin Gene Related Peptide Gene Polymorphism in Migraine Patients

(SEPT)

\section{CALCIFICATION}

Calcified Brain Metastases from Osteosarcoma (MAR)

\section{CANADA}

Epilepsy Care and Research in Canada

(JULY)

\section{CARDIOPULMONARY DYSFUNCTIONS}

Pulmonary Edema and Simultaneous Cardiac Dysfunction After Epileptic Seizures

\section{CARDIOVASCULAR AUTONOMIC REFLEXES}

A Step Toward Moving Forward in Autonomic Nervous System Research

\section{CARDIOVASCULAR DISEASE}

Early Detection for Maximizing Stroke Prevention

(MAR)

\section{CAREGIVING}

When Dementia is in the House: Needs Assessment

Survey for Young Caregivers

\section{CAROTID ARTERY}

Duplication of the Extracranial Internal Carotid Artery Analyzed by MRI

(MAY)

\section{CAROTID ENDARTERECTOMY}

Wait Times for Carotid Endarterectomy, London Ontario 2006-2007

Urgent Carotid Revascularization: The Gap Between Guidelines and Reality

(MAY)

Delays in Carotid Endarterectomy: The Process is the Problem (JULY)

\section{CCSVI}

An Observational Study of Venoplasty in Patients with Multiple Sclerosis (MAR)

Clinical Outcomes in Multiple Sclerosis Patients Following Venous Angioplasty

(MAR)

CEREBELLAR

Multifocal Cerebellar Liponeurocytoma

$(\mathrm{NOV})$

\section{CEREBELLUM}

The Role of the Cerebellum in the Pathophysiology of

\section{CEREBRAL ARTERIOVENOUS} MALFORMATIONS

Long-term Results of Radiosurgery for Cerebral Arteriovenous Malformations

\section{CEREBRAL ISCHEMIA}

The Expression of FOXJ1 in Neurogenesis after

Transient Focal Cerebral Ischemia

(MAY)

\section{CEREBRAL VENOUS SINUS THROMBOSIS}

Reversible Parkinsonian Features in Deep Cerebral

Venous Sinus Thrombosis

(SEPT)

\section{CGRP}

Calcitonin Gene Related Peptide Gene Polymorphism in Migraine Patients

(SEPT)

\section{CHEMOTAXIS}

Advances in Experimental and Clinical Studies of

Chemotaxis

\section{CHILDREN}

Spontaneous Blink Rates in Children During Different Types of Eye Movements

(SEPT)

\section{CHOLINESTERASE INHIBITORS}

Cholinesterase Inhibitors in Vascular Cognitive Impairment

CHOLINESTERASE INHIBITOR TREATMENT

Persistence with Cholinesterase Inhibitor Treatment in Alzheimer's Disease

(SEPT)

\section{CHRONIC CONSTRICTION INJURY}

Hydrogen-Rich Saline Attenuated Neuropathic Pain by Reducing Oxidative Stress

(NOV)

CHRONIC INFLAMMATORY DEMYELINATING POLYNEUROPATHY

Chronic Inflammatory Demyelinating Polyneuropathy and Metastatic Melanoma

(SEPT)

\section{CHRONIC SUBDURAL HEMATOMA}

One Versus Double Burr Holes for Treating Chronic

Subdural Hematoma Meta-Analysis

(JAN)

CIDP

Home IVIG for CIDP: A Focus on Patient Centred Care

(MAY)

\section{CIPROFLOXACIN}

Ciprofloxacin Induced Acute Small Fibre Neuropathy. Case Report

\section{CIRCLE OF WILLIS}

Persistent Trigeminal Artery: An Unusual Rescue Vessel Collateralization?

CLINICAL NEUROPATHOLOGICAL CONFERENCE

CNPC: A Case of Stroke and Blindness

(SEPT)

\section{CLINICAL OUTCOMES}

Association of Serum Bilirubin with Stroke Severity and Clinical Outcomes

\section{CLINICAL RESEARCH}

Establishing a Canadian Registry of Patients with Amyotrophic Lateral Sclerosis

\section{CLINICAL TRIALS}

Experiences with the Execution of Intercultural, Intercontinental Trials - Part I

Unique Experiences with Intercontinental Trials in Stroke - Part II (SEPT)

\section{COAGULOPATHY}

Rapid Resolution of Acute Subdural Hematoma in a Coagulopathic Patient

\section{COGNITIVE IMPAIRMENT}

Screening for Cognitive Impairment in a Stroke Prevention Clinic Using the MoCA (MAR)

Value of the MoCA Test as a Screening Instrument in Multiple Sclerosis (MAY)

Visual Hallucinations and Cognitive Impairment in Parkinson's Disease (SEPT) 


\section{CONCUSSIONS}

Evaluation of a Bicycle Helmet Safety Program for Children

(SEPT)

\section{CONGENITAL OCULAR MOTOR APRAXIA}

The Syndrome of Infantile-Onset Saccade Initiation Delay

\section{COPY NUMBER VARIATION}

Hippocampal Malrotation is Associated with Chromosome 22q11.2 Microdeletion

(SEPT)

\section{CORTICAL LESIONS}

Where are Cortical Lesions Responsible for Opercular Syndrome?

$(\mathrm{JAN})$

\section{CRANIAL NERVE PALSIES}

A Case of Collet-Sicard Syndrome Caused by Necrotizing Otitis Externa

(MAR)

\section{CRANIOTOMY}

One Versus Double Burr Holes for Treating Chronic

Subdural Hematoma Meta-Analysis

(JAN)

\section{CRITICAL CARE MEDICINE}

Intra-abdominal T-cell Lymphoma Presenting with Seizures and MRI Changes

(MAY)

\section{CT PERFUSION}

CT Perfusion in the Management of Acute Stroke

(JULY)

\section{CUSHING'S DISEASE}

Impact of Technique on Cushing Disease Outcome Using Strict Remission Criteria

(MAY)

\section{DELAY}

Delays in Carotid Endarterectomy: The Process is the Problem

(JULY)

\section{DELIRIUM}

Delirium After Gabapentin Withdrawal. Case Report.

\section{DEMENTIA}

Less Education Predicts Anticholinesterase

Discontinuation in Dementia Patients

Preserved Drawing in a Sculptor with Dementia

\section{DEPRESSION}

Discrimination of the Cognitive Profiles of MCI and

Depression using the KBNA

(SEPT)

\section{DEPTH ELECTRODE}

Depth Electrodes in Pediatric Epilepsy Surgery (JAN)

\section{DERMAL SINUS}

Conflicting Diagnosis of Dermal Sinus Tract and Tethered Cord

\section{DEVELOPMENTAL DELAY}

Array CGH Analysis and Developmental Delay: A

Diagnostic Tool for Neurologists

\section{DIABETES}

Diabetes, Intracranial Stenosis and Microemboli in

Asymptomatic Carotid Stenosis

(MAR)

Early Detection for Maximizing Stroke Prevention

(MAR)

DIAPHRAGM

ATTR Amyloidosis Complicated by Phrenic Nerve

Palsy

(JAN)

\section{DIFFERENTIALLY EXPRESSED GENES}

Screening of Key Genes Associated with Ischemic

Stroke via Microarray Data

(NOV)

\section{DIFFUSION TENSOR TRACTOGRAPHY}

fMRI-Driven DTT Assessment of Corticospinal Tracts

Prior to Cortex Resection

(JULY)

\section{DISCONTINUATION}

Less Education Predicts Anticholinesterase

Discontinuation in Dementia Patients

(SEPT)

\section{DISEASE}

The Burden of Inpatient Neurologic Disease in a

Tropical African Hospital

(JULY)

\section{DISEASE-MODIFYING THERAPY}

Multiple Sclerosis Disease-Modifying Therapy

Prescribing Patterns in Ontario

Utility of the Canadian Treatment Optimization

Recommendations (TOR) in MS Care

\section{DONEPEZIL}

Cognitive Change in Donepezil Treated Patients with Vascular or Mixed Dementia

(JULY)

\section{DOUBLE VISION}

Parinaud's Syndrome Due to Migraine

(JAN)

DRIVING

First Seizure While Driving (FSWD) - An

Underestimated Phenomenon?

\section{DRUG-INDUCED PARKINSONISM}

Nonmotor Symptoms in Drug-Induced Parkinsonism and Drug-Naïve Parkinson Disease

\section{DUPLICATION}

Duplication of the Extracranial Internal Carotid Artery Analyzed by MRI

(MAY)

\section{DYSTROGLYCANS}

Inflammatory Changes in Limb Girdle Muscular Dystrophy Type 2I

(NOV)

\section{ECONOMIC EVALUATION}

The Technique and Cost of Radiosurgery for the

Treatment of 1-3 Brain Metastases

(NOV)

EDITORIAL

Non-Motor Symptoms and Parkinsonism (JAN) Gratitude
Early Detection for Maximizing Stroke Prevention

(MAR)

Clinical Outcomes in Multiple Sclerosis Patients

Following Venous Angioplasty (MAR)

Understanding and Managing Spontaneous Intracranial Hypotension (MAR)

Nonlesional Focal Epilepsy: A Challenge from Genes to Surgery (MAR)

Gratification, Masturbation or Paroxysmal Hyperkinetic Motor Syndrome of Infancy? (MAY)

Defining the Optimal Management for Patients with Large Vestibular Schwannomas (MAY)

DMDs Are an Essential Issue But Are They the Only Issue in MS Treatment? (MAY)

Bringing a Little Order to the Chaos: From the Operating Room, and Beyond (MAY)

Urgent Carotid Revascularization: The Gap Between Guidelines and Reality (MAY)

Databases and Registries on Traumatic Spinal Cord Injury in Canada (JULY)

Treating Neurological Wilson's Disease; The Expert Opinion is not Good Enough (JULY)

Cholinesterase Inhibitors in Vascular Cognitive Impairment (JULY)

Evidence-Based Medicine 20 Years On: A View from the Inside (JULY)

A Role for the Surgeon-Scientist? What Does the "Evidence" Tell Us? (JULY)

Epilepsy Care and Research in Canada (JULY)

Message from the New Editor-in-Chief (JULY)

Persistence with Cholinesterase Inhibitor Treatment in Alzheimer's Disease $\quad$ (SEPT)

A Real-World Glimpse into the Epidemiology of ALS in Canada (SEPT)

Hippocampal Malrotation and Temporal Lobe Epilepsy: What is the Relationship? (SEPT)

Salvage Radiosurgery for High Grade Glioma in the Era of Modern Systemic Therapy (NOV)

A Step Toward Moving Forward in Autonomic Nervous System Research (NOV)

Diagnostic Challenges of Radiation Necrosis (NOV)

Symptomatic Cerebral Edema Following Radiosurgery for AVMs

(NOV)

\section{EDUCATION}

Evaluation of a Bicycle Helmet Safety Program for Children

(SEPT)

\section{EDUCATION CORRECTION}

Correcting the MoCA for Education: Effect on Sensitivity

\section{EFFICACY}

Bevacizumab Use for Recurrent High-Grade Glioma at McGill University Hospital

(MAR)

\section{ELECTRODIAGNOSIS}

Clinical Predictors of EMG-confirmed Cervical and Lumbosacral Radiculopathy

(MAR) 


\section{ENDOMETRIOMA}

An Unusual Mass at the Abdominal Site of a Ventriculoperitoneal Shunt

(MAR)

\section{ENDOMETRIOSIS}

An Unusual Mass at the Abdominal Site of a Ventriculoperitoneal Shunt

(MAR)

\section{ENDOSCOPIC TRANSPHENOIDAL SURGERY}

Impact of Technique on Cushing Disease Outcome

Using Strict Remission Criteria

(MAY)

\section{EPIDEMIOLOGICAL SURVEILLANCE}

Epidemiological Surveillance of Amyotrophic Lateral

Sclerosis in Saguenay Region

(SEPT)

\section{EPIDEMIOLOGY}

A Real-World Glimpse into the Epidemiology of ALS in Canada

(SEPT)

\section{EPIGENETICS}

Life Experience and DNA Polymorphisms Influence the Brain Epigenone

(SEPT)

\section{EPILEPSY}

45-Year-Old Female with a 25 Year History of Seizures

Ketogenic Diet

(JAN)

Nonlesional Focal Epilepsy: A Challenge from Gene

to Surgery (MAR)

Epilepsy Care and Research in Canada (JULY)

\section{EPILEPSY CARE}

Epilepsy Care and Research in Canada (JULY)

\section{EPILEPSY MONITORING UNIT}

Predictors of Surgical Candidacy in 414 Epilepsy

Patients Admitted to the EMU

(MAY)

\section{EPILEPSY SURGERY}

Depth Electrodes in Pediatric Epilepsy Surgery (JAN) Predictors of Surgical Candidacy in 414 Epilepsy

Patients Admitted to the EMU

(MAY)

\section{EPILEPTIC SEIZURES}

Pulmonary Edema and Simultaneous Cardiac

Dysfunction After Epileptic Seizures

(NOV)

\section{EUGENICS}

Scandinavian Neuroscience during the Nazi Era

(JULY)

\section{EUTHANASIA}

Scandinavian Neuroscience during the Nazi Era

$$
\text { (JULY) }
$$

\section{EVIDENCE-BASED MEDICINE}

The Evidence-based Medicine Paradigm: Where are We 20 Years Later? Part 1

The Evidence-based Medicine Paradigm: Where are

We 20 Years Later? Part 2

(JULY)
A Viewpoint about the Treatment of Wilson's Disease

$$
\text { (JULY) }
$$

Evidence-Based Medicine 20 Years On: A View from the Inside

(JULY)

\section{EXECUTIVE DYSFUNCTION}

Cognitive Change in Donepezil Treated Patients with Vascular or Mixed Dementia

(JULY)

\section{FAMILIAL AMYLOID NEUROPATHY}

ATTR Amyloidosis Complicated by Phrenic Nerve Palsy

\section{FATTY ACIDS}

Can Behenic Acid (C22:0) Levels be a Prognostic

Factor in Glial Tumors?

(NOV)

\section{FIBER TRACTOGRAPHY}

Tractography of Persistent Ipsilateral Hemiparesis

Following Subdural Hematoma

\section{FIRST SEIZURE}

First Seizure While Driving (FSWD) - An

Underestimated Phenomenon?

(JULY)

\section{FORNIX}

Acute-Onset Anterograde Amnesia Caused by Isolated Bilateral Fornix Infarction

(SEPT)

FOXJ1

The Expression of FOXJ1 in Neurogenesis after Transient Focal Cerebral Ischemia

(MAY)

\section{FRONTOTEMPORAL DEMENTIA}

When Dementia is in the House: Needs Assessment

Survey for Young Caregivers

\section{FROZEN SHOULDER}

Screening for Adhesive Capsulitis in the Timely

Diagnosis of Parkinson's Disease

\section{FUNCTIONAL IMAGING}

Pure Graphogenic Epilepsy - A Rare Form of Reflex Epilepsy

(JULY)

\section{FUNCTIONAL MRI}

Where are Cortical Lesions Responsible for Opercular Syndrome?

(JAN)

fMRI-Driven DTT Assessment of Corticospinal Tracts

Prior to Cortex Resection

(JULY)

\section{GABAPENTIN}

Delirium After Gabapentin Withdrawal. Case Report.

(JAN)

\section{GAMMA KNIFE}

Gamma Knife in the Treatment of Pituitary Adenomas: Results of a Single Center (JULY)

Gamma Knife Radiosurgery for High Grade Glial

Neoplasms: A Canadian Experience $\quad(\mathrm{NOV})$
GELASTIC SEIZURES

Sleep-laughing - Hypnogely

GENE

IL-6 Gene Variation in Parkinson's Disease

(MAR)

\section{GENETICS}

Spinocerebellar Ataxia Presenting in the Eighth Decade of Life

(JULY)

\section{GLIAL TUMORS}

Can Behenic Acid (C22:0) Levels be a Prognostic Factor in Glial Tumors?

\section{GLIOBLASTOMA}

The Potential Impact of Delayed Radiation Therapy on Patients with Glioblastoma

(NOV)

\section{GLIOMA}

45-Year-Old Female with a 25 Year History of Seizures

Gamma Knife Radiosurgery for High Grade Glial Neoplasms: A Canadian Experience (NOV)

Salvage Radiosurgery for High Grade Glioma in the Era of Modern Systemic Therapy (NOV)

\section{GLIONEURONAL}

Rosette-forming Glioneuronal Tumors in the Posterior Third Ventricle

(NOV)

\section{GLOBAL NEUROLOGY}

World Federation of Neurology: Moving into the Future

(JULY)

\section{GLUTAMATE}

Mechanisms Underlying Taurine Protection Against Glutamate-Induced Neurotoxicity

(SEPT)

\section{GOOD WORK}

Feasibility of a Dual Neurosurgeon-Scientist Career in Canada: A Survey Study

GRADE

The Evidence-based Medicine Paradigm: Where are We 20 Years Later? Part 2

(JULY)

\section{GRADIENT ECHO IMAGING}

The Value of GRE, ADC and Routine MRI in Distinguishing Parkinsonian Disorders

\section{GRATIFICATION}

Long-term Outcome of Infantile Gratification Phenomena

Gratification, Masturbation or Paroxysmal Hyperkinetic Motor Syndrome of Infancy?

(MAY)

GRATITUDE

Gratitude 


\section{GUILLAIN-BARRÉ SYNDROME}

Clinically Silent Posterior Reversible Encephalopathy in Guillain-Barré Syndrome

(MAR)

\section{HASHIMOTO'S ENCEPHALOPATHY}

Rigidity and HyperCKemia as Presenting Signs of

Hashimoto's Encephalopathy

(SEPT)

\section{HEAD AND NECK INFECTION}

A Case of Collet-Sicard Syndrome Caused by

Necrotizing Otitis Externa

(MAR)

\section{HEALTH PROMOTION}

Prevalence of Lifestyle Risk Factors in Myotonic Dystrophy Type 1

$(\mathrm{JAN})$

\section{HEALTH STATUS}

Perceptions of Health Status in Multiple Sclerosis Patients and Their Doctors

(MAR)

\section{HEARING RECOVERY}

Recovery from Deafness in the Contralateral Ear of Surgery in NF 2 Patient

(SEPT)

\section{HELMETS}

Evaluation of a Bicycle Helmet Safety Program for Children

\section{HER2NEU AMPLIFICATION}

Her2neu Amplification Associates with Co-deletion $1 \mathrm{p} / 14 \mathrm{q}$ in Recurrent Meningiomas

(MAY)

\section{HIGH-GRADE GLIOMA}

Bevacizumab Use for Recurrent High-Grade Glioma at McGill University Hospital

(MAR)

\section{HIPPOCAMPAL MALROTATION}

Hippocampal Malrotation is Associated with Chromosome 22q11.2 Microdeletion (SEPT)

Hippocampal Malrotation and Temporal Lobe Epilepsy: What is the Relationship?

\section{HISTORY OF NEUROSCIENCES}

Niels Stensen: A 17th Century Scientist with a Modern

View of Brain Organization

(JULY)

HIV

Bilateral Peripheral Facial Paralysis Combined with HIV Meningitis

(NOV)

\section{HOME IVIG}

Home IVIG for CIDP: A Focus on Patient Centred

Care

(MAY)

\section{HOT CROSS BUN SIGN}

The "Hot Cross Bun" Sign in Leptomeningeal

Carcinomatosis

(JULY)

\section{HYDROCEPHALUS}

Intracardiac Migration of a Ventriculoperitoneal Shunt

(SEPT)

\section{HYDROGEN-RICH SALINE}

Hydrogen-Rich Saline Attenuated Neuropathic Pain by

Reducing Oxidative Stress

(NOV)

\section{HYPERAMMONEMIA}

Recurrent Encephalopathy: NAGS (N-

AcetylglutamateSynthase) Deficiency in Adults

\section{HYPERCKEMIA}

Rigidity and HyperCKemia as Presenting Signs of

Hashimoto's Encephalopathy

(SEPT)

\section{HYPOKINESIA}

Reversible Parkinsonian Features in Deep Cerebral

Venous Sinus Thrombosis

(SEPT)

\section{HYPOTENSION}

Spontaneous Intracranial Hypotension:

Recommendations for Management

(MAR)

Understanding and Managing Spontaneous Intracrania Hypotension

(MAR)

ICP

A Unique Model for Ultrasound Assessment of Optic

Nerve Sheath Diameter (MAR

ICP Monitoring - Interpreting the Literature and

Evaluating Practice

(MAY)

Response to Letter: ICP Monitoring - Interpreting the

Literature and Evaluating Practice

(MAY)

\section{ICTAL ASYSTOLE}

Response of Ictal Asystole to Pacemaker Implantation Documented by Video-EEG/ECG

(JULY)

\section{IL-6}

IL-6 Gene Variation in Parkinson's Disease (MAR)

\section{IMMUNE RESPONSE}

Screening of Key Genes Associated with Ischemic

Stroke via Microarray Data

(NOV)

\section{INCIDENCE}

Global Incidence and Prevalence of Traumatic Spinal

$$
\text { Cord Injury }
$$

The Incidence and Prevalence of Multiple Sclerosis in Nova Scotia, Canada

(NOV)

\section{INCLUSION BODY MYOSITIS}

Amyloid Myoneuropathy Mimicking Inclusion Body Myositis

(MAR)

\section{INFANT}

Long-term Outcome of Infantile Gratification Phenomena

(MAY)
INFANTILE SPASMS

Genetic Testing of Epileptic Encephalopathies of

Infancy: An Approach

\section{INFARCTION}

Acute-Onset Anterograde Amnesia Caused by Isolated Bilateral Fornix Infarction

(SEPT)

\section{INJECTION DEVICE}

Avonex ${ }^{\circledR}$ PEN Satisfaction and Patients Experience Clinical Trial

(NOV)

\section{INTERFERON BETA-1A}

Avonex ${ }^{\circledR}$ PEN Satisfaction and Patients Experience

Clinical Trial

(NOV)

\section{INTERNAL CAROTID ARTERY}

Persistent Trigeminal Artery: An Unusual Rescue

Vessel Collateralization?

(MAY)

\section{INTERNAL CAROTID ARTERY STENOSIS}

The ICV Sign as a Marker of Increased Cerebral Blood Transit Time

(MAR)

\section{INTERNAL CEREBRAL VEIN}

The ICV Sign as a Marker of Increased Cerebral Blood Transit Time

(MAR)

\section{INTERSEGMENTAI}

Bilateral Type II Persistent Proatlantal Intersegmental Arteries

(NOV)

\section{INTRA-ABDOMINAL T-CELL LYMPHOMA}

Intra-abdominal T-cell Lymphoma Presenting with

Seizures and MRI Changes

(MAY)

\section{INTRACARDIAC MIGRATION}

Intracardiac Migration of a Ventriculoperitoneal Shunt

(SEPT)

INTRACEREBRAL SCHWANNOMA

Intracerebral Schwannoma Mimicking Meningioma: Case Report

(NOV)

\section{INTRACRANIAI}

Spontaneous Intracranial Hypotension:

Recommendations for Management (MAR)

Understanding and Managing Spontaneous Intracranial Hypotension

Rapid Resolution of Acute Subdural Hematoma in a

Coagulopathic Patient

(JULY)

\section{INTRACRANIAL ANEURYSM}

Size Ratio: A Morphological Factor Predictive of the Rupture of Cerebral Aneurysm?

(MAY)

\section{INTRACRANIAL GERMINOMA}

\section{Intracranial Germinoma with Leptomeningeal Seeding} Along Both Trigeminal Nerves

\section{H. ROYDEN JONES}

H. Royden Jones (1936 - 2013) 


\section{INTRAMEDULLARY MELANOMA}

Primary Spinal Malignant Melanoma of Spinal Cord and Conus Medullaris

(JAN)

\section{IPSILATERAL HEMIPARESIS}

Tractography of Persistent Ipsilateral Hemiparesis

Following Subdural Hematoma

(JULY)

\section{ISCHEMIA}

Acute Neurological Complication in Awake Craniotomy; - A Diagnostic Dilemma

(JULY)

\section{ISCHEMIC STROKE}

The ICV Sign as a Marker of Increased Cerebral Blood

Transit Time

(MAR)

Screening of Key Genes Associated with Ischemic

Stroke via Microarray Data

(NOV)

\section{ISOLATED SULFITE OXIDASE DEFICIENCY}

Preimplantation Genetic Diagnosis in Isolated Sulfite Oxidase Deficiency

(JAN)

\section{JOURNAL}

Gratitude

(MAR)

\section{KETOGENIC DIET}

Ketogenic Diet

(MAR)

\section{LANGUAGE}

Presurgical Language fMRI and Postsurgical Deficits: A Single Centre Experience

$(\mathrm{NOV})$

LARGE

Gamma Knife Radiosurgery for Large Vestibular Schwannomas: A Canadian Experience

(MAY)

\section{LATERAL MEDULLARY INFARCTION}

Pure Dermatomal Sensory Deficits in Lateral Medullary Infarction

(NOV)

\section{LEPTOMENINGEAL CARCINOMATOSIS \\ The "Hot Cross Bun" Sign in Leptomeningeal \\ Carcinomatosis}

(JULY)

\section{LEPTOMENINGEAL SEEDING}

Intracranial Germinoma with Leptomeningeal Seeding Along Both Trigeminal Nerves

(MAY)

\section{LEUKOARAIOSIS}

Screening for Cognitive Impairment in a Stroke Prevention Clinic Using the MoCA

(MAR)

\section{LEVELS OF EVIDENCE}

The Evidence-based Medicine Paradigm: Where are We 20 Years Later? Part 1

The Evidence-based Medicine Paradigm: Where are We 20 Years Later? Part 2 (JULY)

Evidence-Based Medicine 20 Years On: A View from the Inside

(JULY)

\section{LEVETIRACETAM}

Levetiracetam Induced Acute Pancreatitis Case in Pregnancy

(NOV)

\section{LIMB GIRDLE}

Inflammatory Changes in Limb Girdle Muscular Dystrophy Type 2I

(NOV)

\section{LIPONEUROCYTOMA}

Multifocal Cerebellar Liponeurocytoma

$(\mathrm{NOV})$

\section{MAGNETIC RESONANCE IMAGING}

Prevalence of Nonlesional Focal Epilepsy in an Adult Epilepsy Clinic

(MAR)

\section{MAPLE SYRUP URINE DISEASE}

MRI Findings of Adult Maple Syrup Urine Disease

Exacerbation

(MAR)

\section{MASTURBATION}

Long-term Outcome of Infantile Gratification Phenomena (MAY)

Gratification, Masturbation or Paroxysmal Hyperkinetic Motor Syndrome of Infancy? (MAY)

\section{MELANOMA}

Primary Spinal Malignant Melanoma of Spinal Cord and Conus Medullaris (JAN)

Chronic Inflammatory Demyelinating Polyneuropathy and Metastatic Melanoma

(SEPT)

\section{MENINGIOMA}

Her2neu Amplification Associates with Co-deletion $1 \mathrm{p} / 14 \mathrm{q}$ in Recurrent Meningiomas

(MAY)

\section{MESOTHELIOMA}

Neurosurgical Management of Intracranial Metastatic Mesothelioma

(NOV)

\section{META-ANALYSIS}

Traumatic Injury and Multiple Sclerosis: A Systematic Review and Meta-Analysis

IL-6 Gene Variation in Parkinson's Disease (MAR) Meta-Analysis on the Association Between the TF Gene rs1049296 and AD

(SEPT)

\section{METRONIDAZOLE}

Neurologic Complications of Metronidazole (NOV)

\section{MICROELECTRODE RECORDING}

Subthalamic Nucleus Deep Brain Stimulation: An Invaluable Role for MER

(JULY)

\section{MIDAZOLAM}

Role of Midazolam in Parkinsonian Tremors: To Use or Not to Use

(JULY)

\section{MIGRAINE}

Parinaud's Syndrome Due to Migraine
Calcitonin Gene Related Peptide Gene Polymorphism in Migraine Patients

(SEPT)

\section{MILD COGNITIVE IMPAIRMENT}

Discrimination of the Cognitive Profiles of MCI and Depression using the KBNA

(SEPT)

\section{MINI-ROSENTHAL FIBRES}

Oligodendrogliomas with Abundant Refractile Eosinophilic Granular Cells

(SEPT)

\section{MITOCHONDRIAL DISORDER}

Mitochondrial Depletion Syndromes in Children and Adults

(SEPT)

\section{MITOCHONDRIAL DNA}

Mitochondrial Depletion Syndromes in Children and Adults

MoCA

Correcting the MoCA for Education: Effect on Sensitivity

(SEPT)

\section{MoCA TEST}

Value of the MoCA Test as a Screening Instrument in Multiple Sclerosis

\section{MOLECULAR GENETICS}

Genetic Testing of Epileptic Encephalopathies of Infancy: An Approach

\section{MORPHOLOGY}

Size Ratio: A Morphological Factor Predictive of the Rupture of Cerebral Aneurysm?

(MAY)

\section{MOTION ANALYSIS}

Motion Analysis of Normal Patellar Tendon Reflex

MOTOR

(NOV)

Gratification, Masturbation or Paroxysmal Hyperkinetic Motor Syndrome of Infancy?

(MAY)

\section{MOTOR CORTICAL AREAS}

fMRI-Driven DTT Assessment of Corticospinal Tracts Prior to Cortex Resection

(JULY)

\section{MOVEMENT DISORDERS}

Telehealth Management in Movement Disorder: A Retrospective Study

(MAR)

MRI

MRI Findings of Adult Maple Syrup Urine Disease Exacerbation (MAR)

Correlation Between MRI Findings and Histological

Diagnosis of Brainstem Glioma

(MAY)

Duplication of the Extracranial Internal Carotid Artery Analyzed by MRI (MAY)

Radiologic Patterns of Necrosis After Proton Therapy

(NOV) 


\section{MtDNA DEPLETION \\ Mitochondrial Depletion Syndromes in Children and Adults}

(SEPT)

\section{MULTIMODALITY MONITORING}

ICP Monitoring - Interpreting the Literature and

Evaluating Practice

\section{MULTIPLE SCLEROSIS}

Multiple Sclerosis Disease-Modifying Therapy

Prescribing Patterns in Ontario

(JAN)

Traumatic Injury and Multiple Sclerosis: A Systematic Review and Meta-Analysis

(MAR)

Perceptions of Health Status in Multiple Sclerosis

Patients and Their Doctors

(MAR)

An Observational Study of Venoplasty in Patients with Multiple Sclerosis (MAR)

Clinical Outcomes in Multiple Sclerosis Patients Following Venous Angioplasty

(MAR)

Value of the MoCA Test as a Screening Instrument in Multiple Sclerosis

(MAY)

Treatment Optimization in MS: Canadian MS Working Group Updated Recommendations (MAY)

DMDs Are an Essential Issue But Are They the Only Issue in MS Treatment?

(MAY)

Multiple Sclerosis and Pregnancy: A Comparison Study (JULY)

IL2RA Allele Increases Risk of Neuromyelitis Optica in Southern Han Chinese

(NOV)

The Incidence and Prevalence of Multiple Sclerosis in Nova Scotia, Canada

(NOV)

Normative Data for the Stroop Color Word Test for a North American Population

(NOV)

\section{MULTIPLE SYSTEM ATROPHY}

Early Clinical Features Differentiate Cerebellar Variant MSA and Sporadic Ataxia

(MAR)

\section{MUSCULAR DYSTROPHIES}

Inflammatory Changes in Limb Girdle Muscular

Dystrophy Type 2I

(NOV)

\section{MUTATION ANALYSIS}

Diversity of ARSACS Mutations in French-Canadians

(JAN)

\section{MYOPATHY}

Amyloid Myoneuropathy Mimicking Inclusion Body Myositis

(MAR)

\section{NAG SYNTHASE}

Recurrent Encephalopathy: NAGS (N-Acetylglutamate Synthase) Deficiency in Adults

\section{NASCET}

Experiences with the Execution of Intercultural, Intercontinental Trials - Part

\section{NAZI EUROPE}

To the Editor - RE: Neuroscience in Nazi Europe Part III: Victims of the Third Reich

\section{NERVE REGENERATION}

Advances in Experimental and Clinical Studies of

Chemotaxis

(MAY)

NEURINOMA

Sleep-laughing - Hypnogely

(JULY)

\section{NEURO-ENDOSCOPY}

Endoscopic Associated Iatrogenic Terson's Syndrome

(MAR)

\section{NEUROGENESIS}

The Expression of FOXJ1 in Neurogenesis after

Transient Focal Cerebral Ischemia

(MAY)

\section{NEUROGENETICS}

Preimplantation Genetic Diagnosis in Isolated Sulfite

Oxidase Deficiency

$(\mathrm{JAN})$

\section{NEUROGENIC PULMONARY EDEMA}

Pulmonary Edema and Simultaneous Cardiac

Dysfunction After Epileptic Seizures

$(\mathrm{NOV})$

\section{NEUROIMAGE}

Neuropsychiatric Lupus: Classification Criteria in Neuroimaging Studies

(MAY)

\section{NEURO-IMAGING}

Acute Fulminant Hepatic Failure, Encephalopathy and Early CT Changes

(JULY)

\section{NEUROINVASIVE WEST NILE}

Neuroinvasive West Nile Virus Disease in Canada. The Saskatchewan Experience

(JULY)

\section{NEUROLOGICAL}

The Burden of Inpatient Neurologic Disease in a

Tropical African Hospital

(JULY)

\section{NEUROLOGY}

Less Education Predicts Anticholinesterase

Discontinuation in Dementia Patients

(SEPT)

\section{NEUROMUSCULAR DISEASE}

The CNDR: Collaborating to Translate New Therapies for Canadians

(SEPT)

\section{NEUROMUSCULAR DISORDERS}

Prevalence of Lifestyle Risk Factors in Myotonic

Dystrophy Type 1

(JAN)

\section{NEUROMYELITIS OPTICA}

IL2RA Allele Increases Risk of Neuromyelitis Optica

in Southern Han Chinese

(NOV)

\section{NEUROPATHOLOGY}

Canadian Association of Neuropathologists ABSTRACTS

\section{NEUROPROTECTION}

Mechanisms Underlying Taurine Protection Against Glutamate-Induced Neurotoxicity
NEUROPSYCHIATRIC

Neuropsychiatric Lupus: Classification Criteria in Neuroimaging Studies

(MAY)

NEUROSCIENCE RESEARCH

Feasibility of a Dual Neurosurgeon-Scientist Career in

$$
\text { Canada: A Survey Study }
$$

A Role for the Surgeon-Scientist? What Does the

"Evidence" Tell Us?

\section{NEUROSURGEON}

Dr. Peter B.R. Allen, an Albertan Neurosurgeon:

$(1932-2013)$

\section{NEUROSURGERY RESEARCH}

Feasibility of a Dual Neurosurgeon-Scientist Career in

$$
\text { Canada: A Survey Study }
$$

A Role for the Surgeon-Scientist? What Does the

"Evidence" Tell Us?

\section{NEUROTOXICITY}

Neurologic Complications of Metronidazole (NOV)

\section{NIELS STENSEN}

Niels Stensen: A 17th Century Scientist with a Modern View of Brain Organization

(JULY)

\section{NONLESIONAL FOCAL EPILEPSY}

Prevalence of Nonlesional Focal Epilepsy in an Adult Epilepsy Clinic

(MAR)

Nonlesional Focal Epilepsy: A Challenge from Genes to Surgery (MAR)

\section{NON-MOTOR SYMPTOMS}

Nonmotor Symptoms in Drug-Induced Parkinsonism and Drug-Naïve Parkinson Disease

Non-Motor Symptoms and Parkinsonism (JAN)

\section{NORMAL PRESSURE HYDROCEPHALUS}

Social Support in Normal Pressure Hydrocephalus:

Unmet Tangible Social Support

(JAN)

\section{NORMATIVE DATA}

Normative Data for the Stroop Color Word Test for a North American Population

The Autonomic Reflex Screen in Healthy Participants from Southwestern Ontario (NOV)

\section{NURSING}

Telehealth Management in Movement Disorder: A Retrospective Study

(MAR)

\section{OBITUARY}

Peter Seland (1941-2013)

(SEPT)

Dr. Peter B.R. Allen, an Albertan Neurosurgeon:

$$
(1932 \text { - 2013) }
$$

H. Royden Jones (1936 - 2013)

\section{OLIGODENDROGLIOMA}

Oligodendrogliomas with Abundant Refractile Eosinophilic Granular Cells 


\section{ON-THE-SPOT TURNS \\ Parkinson's Disease and Segmental Coordination during Turning: I. Standing Turns}

(JULY)

\section{OPERCULAR SYNDROME}

Where are Cortical Lesions Responsible for Opercular Syndrome?

(JAN)

\section{OPTIC NERVE SHEATH}

A Unique Model for Ultrasound Assessment of Optic Nerve Sheath Diameter

(MAR)

\section{OPTIMIZING TREATMENT \\ Treatment Optimization in MS: Canadian MS Working \\ Group Updated Recommendations (MAY) \\ DMDs Are an Essential Issue But Are They the Only \\ Issue in MS Treatment? \\ (MAY)}

\section{OSTEOSARCOMA}

Calcified Brain Metastases from Osteosarcoma (MAR)

\section{PACEMAKER}

Response of Ictal Asystole to Pacemaker Implantation Documented by Video-EEG/ECG

(JULY)

\section{PARANEOPLASTIC NEUROLOGICAL SYNDROME}

Chronic Inflammatory Demyelinating Polyneuropathy and Metastatic Melanoma

\section{PARASOMNIA}

Sleep-laughing - Hypnogely

(JULY)

\section{PARINAUD'S SYNDROME}

Parinaud's Syndrome Due to Migraine

\section{PARKINSONISM}

Hemiparkinsonism Due to Coiled Posterior Cerebral Artery Aneurysm

Reversible Parkinsonian Features in Deep Cerebral Venous Sinus Thrombosis

\section{PARKINSON'S DISEASE}

Serum Urate and the Risk of Parkinson's Disease:

Results from a Meta-Analysis

Nonmotor Symptoms in Drug-Induced Parkinsonism and Drug-Naïve Parkinson Disease $\quad$ (JAN)

Non-Motor Symptoms and Parkinsonism (JAN)

The Role of the Cerebellum in the Pathophysiology of

Parkinson's Disease

(MAY)

Parkinson's Disease and Segmental Coordination during Turning: I. Standing Turns

Parkinson's Disease and Segmental Coordination during Turning: II. Walking Turns (JULY)

Visual Hallucinations and Cognitive Impairment in Parkinson's Disease (SEPT)

Effectiveness of BoNT A in Parkinson Disease Upper Limb Tremor Management (SEPT)
PARKINSON'S DISEASE SYMPTOMS

Screening for Adhesive Capsulitis in the Timely

Diagnosis of Parkinson's Disease

(JAN)

\section{PATHOLOGY}

Correlation Between MRI Findings and Histological

Diagnosis of Brainstem Glioma

(MAY)

Intracerebral Schwannoma Mimicking Meningioma:

Case Report

(NOV)

\section{PATIENT PERCEPTIONS}

Perceptions of Health Status in Multiple Sclerosis

Patients and Their Doctors

(MAR)

\section{PATIENT SATISFACTION}

Avonex ${ }^{\circledR}$ PEN Satisfaction and Patients Experience

Clinical Trial

(NOV)

\section{PEDIATRICS}

Depth Electrodes in Pediatric Epilepsy Surgery (JAN)

\section{PENCILLAMINE}

A Viewpoint about the Treatment of Wilson's Disease

(JULY)

\section{PERSISTENT}

Bilateral Type II Persistent Proatlantal Intersegmental Arteries

(NOV)

\section{PERSISTENT TRIGEMINAL ARTERY}

Persistent Trigeminal Artery: An Unusual Rescue

Vessel Collateralization?

(MAY)

\section{PET}

Radiologic Patterns of Necrosis After Proton Therapy of Skull Base Tumors

(NOV)

\section{PETER ALLEN}

Dr. Peter B.R. Allen, an Albertan Neurosurgeon: (1932-2013)

(NOV)

\section{PETER SELAND}

Peter Seland (1941-2013)

(SEPT)

\section{PITUITARY}

Pituitary Abscess: Review and Highlight of a Case

$$
\text { Mimicking Pituitary Apoplexy }
$$

(SEPT)

\section{PITUITARY ADENOMA}

Impact of Technique on Cushing Disease Outcome

Using Strict Remission Criteria

(MAY)

Gamma Knife in the Treatment of Pituitary Adenomas:

Results of a Single Center

(JULY)

\section{POLYMYOSITIS}

Inflammatory Changes in Limb Girdle Muscular Dystrophy Type 2I

(NOV)

\section{POPULATION-BASED STUDY}

Epidemiological Surveillance of Amyotrophic Lateral Sclerosis in Saguenay Region
POSTERIOR REVERSIBLE ENCEPHALOPATHY SYNDROME

Clinically Silent Posterior Reversible Encephalopathy in Guillain-Barré Syndrome

(MAR)

Posterior Reversible Encephalopathy Syndrome - A Rare Complication of Bee-Stings

(MAY)

\section{POSTERIOR THIRD VENTRICLE}

Rosette-forming Glioneuronal Tumors in the Posterior Third Ventricle

(NOV)

\section{POST-PARTUM}

Benign Post-Partum Reversible Restricted Diffusion Lesion of the Splenium

\section{POSTSURGICAL DEFICITS}

Presurgical Language fMRI and Postsurgical Deficits: A Single Centre Experience (NOV)

\section{PREGNANCY}

Multiple Sclerosis and Pregnancy: A Comparison Study

Levetiracetam Induced Acute Pancreatitis Case in Pregnancy

(NOV)

\section{PREIMPLANTATION GENETIC DIAGNOSIS}

Preimplantation Genetic Diagnosis in Isolated Sulfite Oxidase Deficiency

(JAN)

\section{PRESCRIBING PATTERNS}

Multiple Sclerosis Disease-Modifying Therapy

Prescribing Patterns in Ontario

(JAN)

\section{PRESURGICAL IMRI}

Presurgical Language fMRI and Postsurgical Deficits: A Single Centre Experience

(NOV)

\section{PREVALENCE}

Prevalence of Nonlesional Focal Epilepsy in an Adult Epilepsy Clinic

(MAR)

Global Incidence and Prevalence of Traumatic Spinal Cord Injury

(MAY)

The Incidence and Prevalence of Multiple Sclerosis in Nova Scotia, Canada

(NOV)

\section{PRIMARY}

Primary Spinal Malignant Melanoma of Spinal Cord and Conus Medullaris

\section{PRIORITY SETTING}

Priority Setting in Neurosurgery as Exemplified by an Everyday Challenge (MAY)

Bringing a Little Order to the Chaos: From the Operating Room, and Beyond

\section{PROATLANTAL}

Bilateral Type II Persistent Proatlantal Intersegmental Arteries (NOV) 


\section{PROTON BEAM THERAPY}

Radiologic Patterns of Necrosis After Proton Therapy of Skull Base Tumors

(NOV)

\section{PSEN1 MUTATION}

Variant Alzheimer's Disease with Spastic Paraparesis and Supranuclear Gaze Palsy

(MAR)

\section{PSYCHOMETRIC PROPERTIES}

Correcting the MoCA for Education: Effect on Sensitivity

(SEPT)

\section{QSART}

A Step Toward Moving Forward in Autonomic Nervous System Research

(NOV)

\section{RACIAL HYGIENE}

Scandinavian Neuroscience during the Nazi Era

(JULY)

RADIATION INJURY

Radiologic Patterns of Necrosis After Proton Therapy of Skull Base Tumors

(NOV)

\section{RADIATION NECROSIS}

Diagnostic Challenges of Radiation Necrosis (NOV)

\section{RADIATION THERAPY}

The Potential Impact of Delayed Radiation Therapy on Patients with Glioblastoma

(NOV)

\section{RADICULOPATHY}

Clinical Predictors of EMG-confirmed Cervical and Lumbosacral Radiculopathy

(MAR)

\section{RADIOSURGERY}

Long-term Results of Radiosurgery for Cerebral Arteriovenous Malformations

Gamma Knife Radiosurgery for Large Vestibular Schwannomas: A Canadian Experience (MAY)

Defining the Optimal Management for Patients with Large Vestibular Schwannomas

Factors Determining the Clinical Complications of Radiosurgery for AVM (NOV)

Gamma Knife Radiosurgery for High Grade Glial Neoplasms: A Canadian Experience (NOV)

Salvage Radiosurgery for High Grade Glioma in the Era of Modern Systemic Therapy

RCTs

The Evidence-based Medicine Paradigm: Where are We 20 Years Later? Part 1

(JULY)

\section{RECESSIVE ATAXIA}

Diversity of ARSACS Mutations in French-Canadians

(JAN)

RECOMMENDATIONS

Treatment Optimization in MS: Canadian MS Working Group Updated Recommendations

\section{RECURRENCE}

Her2neu Amplification Associates with Co-deletion $1 \mathrm{p} / 14 \mathrm{q}$ in Recurrent Meningiomas

(MAY)

\section{RECURRENT}

Salvage Radiosurgery for High Grade Glioma in the Era of Modern Systemic Therapy

(NOV)

\section{REFLEX EPILEPSY}

Pure Graphogenic Epilepsy - A Rare Form of Reflex Epilepsy

(JULY)

\section{REFRACTILE GRANULAR EOSINOPHILIC CELLS}

Oligodendrogliomas with Abundant Refractile

Eosinophilic Granular Cells

(SEPT)

\section{REGISTRY}

Establishing a Canadian Registry of Patients with

Amyotrophic Lateral Sclerosis

Databases and Registries on Traumatic Spinal Cord Injury in Canada (MAY)

The CNDR: Collaborating to Translate New Therapies for Canadians

(SEPT)

\section{REGISTRY-BASED STUDY}

Epidemiological Surveillance of Amyotrophic Lateral Sclerosis in Saguenay Region

(SEPT)

\section{RELAPSING-REMITTING MULTIPLE SCLEROSIS}

Utility of the Canadian Treatment Optimization Recommendations (TOR) in MS Care (JULY)

\section{RESECTIVE SURGERY}

Predictors of Surgical Candidacy in 414 Epilepsy Patients Admitted to the EMU (MAY)

\section{RESOURCE ALLOCATION}

Priority Setting in Neurosurgery as Exemplified by an Everyday Challenge (MAY)

Bringing a Little Order to the Chaos: From the Operating Room, and Beyond

(MAY)

\section{RESPIRATORY FAILURE}

ATTR Amyloidosis Complicated by Phrenic Nerve
RGNT

Rosette-forming Glioneuronal Tumors in the Posterior Third Ventricle

(NOV)

\section{RIGIDITY}

Rigidity and HyperCKemia as Presenting Signs of Hashimoto's Encephalopathy (SEPT)

\section{RISK FACTORS}

Prevalence of Lifestyle Risk Factors in Myotonic Dystrophy Type 1

Neuroinvasive West Nile Virus Disease in Canada. The Saskatchewan Experience

(JULY)

\section{RUPTURE RISK}

Size Ratio: A Morphological Factor Predictive of the Rupture of Cerebral Aneurysm?

(MAY)

\section{SACCADE INITIATION DELAY}

The Syndrome of Infantile-Onset Saccade Initiation Delay

(MAR)

\section{SACSIN}

Diversity of ARSACS Mutations in French-Canadians

SEGMENTAL COORDINATION

Parkinson's Disease and Segmental Coordination during Turning: I. Standing Turns

\section{SEGMENTAL REORIENTATION}

Parkinson's Disease and Segmental Coordination during Turning: II. Walking Turns

(JULY)

\section{SEIZURES}

Intra-abdominal T-cell Lymphoma Presenting with Seizures and MRI Changes

\section{SERUM BILIRUBIN}

Association of Serum Bilirubin with Stroke Severity and Clinical Outcomes

\section{SEVERITY}

Association of Serum Bilirubin with Stroke Severity and Clinical Outcomes

\section{SHUNT MIGRATION}

Intracardiac Migration of a Ventriculoperitoneal Shunt (SEPT)

\section{RESTRICTED DIFFUSION}

Benign Post-Partum Reversible Restricted Diffusion

Lesion of the Splenium

\section{REVERSIBLE POSTERIOR}

LEUCOENCEPHALOPATHY SYNDROME

Posterior Reversible Encephalopathy Syndrome - A

Rare Complication of Bee-Stings

(MAY)

\section{REVIEWERS}

Gratitude

\section{SIDE EFFECT}

Ciprofloxacin Induced Acute Small Fibre Neuropathy. Case Report

\section{SIGNALING PATHWAY}

The Expressions of Wnt/ $\beta$-catenin Pathway-Related Components in Brainstem Gliomas

(MAY)

\section{SINGLE NUCLEOTIDE POLYMORPHISM}

Life Experience and DNA Polymorphisms Influence the Brain Epigenome 
IL2RA Allele Increases Risk of Neuromyelitis Optica in Southern Han Chinese

(NOV)

\section{SMALL FIBRE NEUROPATHY \\ Ciprofloxacin Induced Acute Small Fibre Neuropathy.} Case Report

(JAN)

\section{SMALL-GAP SLEEVE BRIDGING}

Advances in Experimental and Clinical Studies of Chemotaxis

(MAY)

\section{SOCIAL SUPPORT}

Social Support in Normal Pressure Hydrocephalus: Unmet Tangible Social Support

(JAN)

\section{SOMATOTOPIC TOPOGRAPHY \\ Pure Dermatomal Sensory Deficits in Lateral Medullary Infarction}

(NOV)

SPARC

SPARC and Vav3 Expression in Meningioma: Factors Related to Prognosis

$(\mathrm{NOV})$

\section{SPINAL CORD INJURY}

Global Incidence and Prevalence of Traumatic Spinal Cord Injury

(MAY)

Databases and Registries on Traumatic Spinal Cord Injury in Canada

(MAY)

\section{SPINOCEREBELLAR ATAXIA}

Spinocerebellar Ataxia Presenting in the Eighth Decade of Life

(JULY)

\section{SPLENIUM}

Benign Post-Partum Reversible Restricted Diffusion

Lesion of the Splenium

(JAN)

\section{SPONTANEOUS}

Spontaneous Intracranial Hypotension

Recommendations for Management

(MAR)

Understanding and Managing Spontaneous Intracranial Hypotension

(MAR)

\section{SPORADIC ATAXIA}

Early Clinical Features Differentiate Cerebellar Variant MSA and Sporadic Ataxia

(MAR)

\section{STEREOTACTIC RADIOSURGERY}

Gamma Knife in the Treatment of Pituitary Adenomas: Results of a Single Center

(JULY)

The Technique and Cost of Radiosurgery for the

Treatment of 1-3 Brain Metastase

$(\mathrm{NOV})$

\section{STIFF-PERSON SYNDROME}

GABAergic Changes in 11C-Flumazenil PET in the Drug-Naïve Stiff-Person Syndrome

(JAN)

\section{STROKE}

Tissue Window in Stroke Thrombolysis Study (TWIST): A Safety Study
CT Perfusion in the Management of Acute Stroke

(JULY)

Delays in Carotid Endarterectomy: The Process is the Problem

(JULY)

CNPC: A Case of Stroke and Blindness $\quad$ (SEPT)

\section{STROKE-ON-AWAKENING}

Tissue Window in Stroke Thrombolysis Study

(TWIST): A Safety Study

\section{STROKE PREVENTION}

Screening for Cognitive Impairment in a Stroke

Prevention Clinic Using the MoCA

(MAR)

Early Detection for Maximizing Stroke Prevention

(MAR)

Experiences with the Execution of Intercultural, Intercontinental Trials - Part I (MAY)

Unique Experiences with Intercontinental Trials in Stroke - Part II

(SEPT)

\section{STROOP COLOR WORD TEST}

Normative Data for the Stroop Color Word Test for a

North American Population

(NOV)

\section{SUBDURAL HEMATOMA}

Tractography of Persistent Ipsilateral Hemiparesis

Following Subdural Hematoma

(JULY)

\section{SUBTHALAMIC NUCLEUS}

Subthalamic Nucleus Deep Brain Stimulation: An

Invaluable Role for MER

(JULY)

\section{SUPRANUCLEAR PALSY}

Variant Alzheimer's Disease with Spastic Paraparesis

and Supranuclear Gaze Palsy

(MAR)

\section{SURVIVAL}

The Potential Impact of Delayed Radiation Therapy on Patients with Glioblastoma

(NOV)

\section{SYSTEMATIC REVIEW}

ICP Monitoring - Interpreting the Literature and

Evaluating Practice

(MAY)

\section{SYSTEMIC LUPUS ERYTHEMATOSUS}

Neuropsychiatric Lupus: Classification Criteria in

$$
\text { Neuroimaging Studies }
$$

\section{TAURINE}

Mechanisms Underlying Taurine Protection Against

$$
\text { Glutamate-Induced Neurotoxicity }
$$

\section{TELEHEALTH}

Telehealth Management in Movement Disorder: A

Retrospective Study

(MAR)

\section{TEMPORAL ARTERITIS}

CNPC: A Case of Stroke and Blindness
TEMPORAL LOBE EPILEPSY

Hippocampal Malrotation and Temporal Lobe Epilepsy: What is the Relationship?

(SEPT)

\section{TENDON REFLEX}

Motion Analysis of Normal Patellar Tendon Reflex

(NOV)

\section{TERSON'S SYNDROME}

Endoscopic Associated Iatrogenic Terson's Syndrome

(MAR)

\section{TETHERED CORD}

Conflicting Diagnosis of Dermal Sinus Tract and

Tethered Cord

\section{THIRD REICH}

To the Editor - RE: Neuroscience in Nazi Europe Part III: Victims of the Third Reich

(MAY)

\section{THROMBOLYSIS}

Tissue Window in Stroke Thrombolysis Study (TWIST): A Safety Study

TIA

Cerebral Amyloid Angiopathy Presenting with TIA-like Episodes

(MAY)

\section{TRANSCRANIAL DOPPLER}

Diabetes, Intracranial Stenosis and Microemboli in Asymptomatic Carotid Stenosis

(MAR)

\section{TRANSFERRIN}

Meta-Analysis on the Association Between the TF Gene rs1049296 and AD

(SEPT)

TRANSLATIONAL NEUROSCIENCE

Life Experience and DNA Polymorphisms Influence the Brain Epigenome

(SEPT)

\section{TRANSLATIONAL RESEARCH}

The CNDR: Collaborating to Translate New Therapies for Canadians

(SEPT)

\section{TRAUMA}

Databases and Registries on Traumatic Spinal Cord

Injury in Canada

(MAY)

\section{TRAUMATIC BRAIN INJURY}

Response to Letter: ICP Monitoring - Interpreting the Literature and Evaluating Practice

(MAY)

\section{TRAUMATIC INJURY}

Traumatic Injury and Multiple Sclerosis: A Systematic Review and Meta-Analysis (MAR)

TREATMENT OPTIMIZATION RECOMMENDATIONS

Utility of the Canadian Treatment Optimization Recommendations (TOR) in MS Care (JULY) 


\section{TREMOR}

Effectiveness of BoNT A in Parkinson Disease Upper

Limb Tremor Management

(SEPT)

\section{TREMORS}

Role of Midazolam in Parkinsonian Tremors: To Use or

Not to Use

(JULY)

\section{TRIGEMINAL NERVE}

Intracranial Germinoma with Leptomeningeal Seeding

Along Both Trigeminal Nerves

(MAY)

\section{TURNING}

Parkinson's Disease and Segmental Coordination during Turning: II. Walking Turns

(JULY)

TYPE 6

Spinocerebellar Ataxia Presenting in the Eighth Decade of Life

(JULY)

\section{ULTRASOUND}

A Unique Model for Ultrasound Assessment of Optic Nerve Sheath Diameter

(MAR)

\section{UREA CYCLE}

Recurrent Encephalopathy: NAGS (N-Acetylglutamate Synthase) Deficiency in Adults

\section{URIC ACID}

Serum Urate and the Risk of Parkinson's Disease:

Results from a Meta-Analysis

\section{VARIANT ALZHEIMER'S DISEASE}

Variant Alzheimer's Disease with Spastic Paraparesis and Supranuclear Gaze Palsy

\section{VASCULAR COGNITIVE IMPAIRMENT}

Cholinesterase Inhibitors in Vascular Cognitive Impairment

\section{VASCULAR DEMENTIA}

Cognitive Change in Donepezil Treated Patients with Vascular or Mixed Dementia (JULY)

\section{VASCULITIS}

CNPC: A Case of Stroke and Blindness

(SEPT)

Vav3

SPARC and Vav3 Expression in Meningioma: Factors

Related to Prognosis

(NOV)

\section{VENOPLASTY}

An Observational Study of Venoplasty in Patients with

Multiple Sclerosis

(MAR)

Clinical Outcomes in Multiple Sclerosis Patients

Following Venous Angioplasty

(MAR)

VENTRICULOPERITONEAL SHUNT

An Unusual Mass at the Abdominal Site of a

Ventriculoperitoneal Shunt

(MAR)

\section{VESTIBULAR SCHWANNOMA}

Gamma Knife Radiosurgery for Large Vestibular Schwannomas: A Canadian Experience (MAY) Defining the Optimal Management for Patients with

Large Vestibular Schwannomas

(MAY)

Recovery from Deafness in the Contralateral Ear of

Surgery in NF 2 Patient

(SEPT)

\section{VIDEO DISPLAY}

Wearable Video Display Allowing Freedom in Head

Positioning for Brain Mapping

(JAN)

\section{VIDEO-EEG}

Response of Ictal Asystole to Pacemaker Implantation Documented by Video-EEG/ECG

(JULY)

VISUAL HALLUCINATIONS

Visual Hallucinations and Cognitive Impairment in

Parkinson's Disease

(SEPT)

\section{VISUOMOTOR TASK}

First Seizure While Driving (FSWD) - An

Underestimated Phenomenon?

\section{VITREOUS HEMORRHAGE}

Endoscopic Associated Iatrogenic Terson's Syndrome

\section{WAIT TIMES}

Wait Times for Carotid Endarterectomy, London Ontario 2006-2007

Urgent Carotid Revascularization: The Gap Between Guidelines and Reality

(MAY)

\section{WEST NILE INFECTION}

Neuroinvasive West Nile Virus Disease in Canada. The Saskatchewan Experience

\section{WEST SYNDROME}

Genetic Testing of Epileptic Encephalopathies of Infancy: An Approach

\section{WILSON'S DISEASE}

A Viewpoint about the Treatment of Wilson's Disease

Treating Neurological Wilson's Disease; The Expert Opinion is not Good Enough

WITHDRAWAL

Delirium After Gabapentin Withdrawal. Case Report.

WNT

The Expressions of Wnt/ $\beta$-catenin Pathway-Related

Components in Brainstem Gliomas

(MAY)

\section{WORLD FEDERATION OF NEUROLOGY}

World Federation of Neurology: Moving into the Future

\section{WRITING EPILEPSY}

Pure Graphogenic Epilepsy - A Rare Form of Reflex Epilepsy

\section{YOUNG CARERS}

When Dementia is in the House: Needs Assessment Survey for Young Caregivers

ZINC

Treating Neurological Wilson's Disease; The Expert Opinion is not Good Enough 